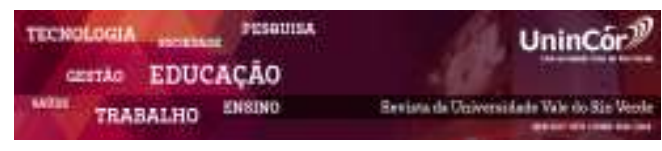

Revista da Universidade Vale do Rio Verde ISSN: 1517-0276 / EISSN: 2236-5362 Vol. 16 | n. 1 | Ano 2018

Marco Aurélio Batista de Sousa Universidade Federal de Mato Grosso do Sul mcbsousa@bol.com.br

Ana Letícia Lima de Oliveira Universidade Federal de Mato Grosso do Sul analeticiall11@gmail.com

Nilton Cezar Carraro

Universidade Federal de Mato Grosso do Sul nilton.carrraro@ufms.br

\section{TÉCNICAS ORÇAMENTÁRIAS UTILIZADAS POR PREFEITURAS DO ESTADO DE MATO GROSSO DO SUL}

\section{RESUMO}

Este trabalho buscou identificar as técnicas orçamentárias utilizadas por Prefeituras do Estado de Mato Grosso do Sul, a fim de identifica-las e destacar os motivos de sua utilização. Para tanto, esta pesquisa foi dividida em duas etapas: a primeira se destinou à parte introdutória do estudo pontuando questões relevantes ao seu desenvolvimento seguido pela revisão da literatura contemplando assuntos pertinentes ao tema, os quais deram sustentação à parte prática. A segunda, por sua vez, foi operacionalizada por meio de um estudo exploratório e descritivo do tipo survey, buscando estabelecer relações entre o referencial teórico do estudo e a realidade das Prefeituras a serem investigadas. Para coletar os dados necessários à sua execução foi utilizado questionário, com questões predominantemente fechadas aplicado via e-mail aos responsáveis pela elaboração do Orçamento Público Municipal, bem como informações disponíveis no site das Prefeituras, utilizando-se para sua análise a abordagem qualitativa. Desde modo, espera-se identificar quais são as Técnicas Orçamentárias mais utilizadas pelas Prefeituras do Estado, bem como os motivos de sua adoção e se estão em consonância com a legislação vigente.

Palavras-chave: Orçamento Público Municipal. Técnicas orçamentarias. Prefeituras do Estado de Mato Grosso do Sul.

\section{TECHNIQUES USED IN MUNICIPALITY BUDGET STATE MATO GROSSO DO SUL}


Keywords: Public budget; Budgeting technique; Mato Grosso do Sul's city halls.

Recebido em: 13/10/2016 - Aprovado em: 10/01/2018 - Disponibilizado em: 15/07/2018

\section{INTRODUÇÃO}

A administração pública tem por objetivo proporcionar o bem-estar à população, mediante a oferta, ampliação e a gestão de bens e serviços de qualidade. Para atender a essa, dentre outras expectativas e demanda da sociedade, o poder público necessita de recursos financeiros.

Estes recursos, em sua maioria são obtidos por meio da arrecadação de tributos os quais de acordo com o Art. $3^{\circ}$ do Código Tributário Nacional representam "toda prestação pecuniária em moeda, ou cujo valor nele possa se exprimir, que não constitua sanção de ato ilícito, instituído em lei e cobrado mediante atividade administrativa plenamente vinculada", ou seja: impostos, taxas e contribuições sociais, econômicas, sindicais e profissionais.

Em relação aos impostos, Mota (2009), destaca-os como sendo toda prestação pecuniária, cuja obrigação tem como fato gerador uma situação independente de qualquer atividade estatal, relativa ao contribuinte, de acordo com a sua capacidade contributiva, como é o caso do imposto de renda da pessoa física. As taxas, por sua vez, representam uma prestação pecuniária de obrigação tributária decorrente de serviço público prestado ou posto à disposição do contribuinte independentemente de uso, como a iluminação pública. E, as contribuições, por sua vez, destinam-se ao custeio e manutenção de obrigações com o fim social, sindical, profissional e de domínio econômico.

A entrada de recursos financeiros, bem como suas aplicações, deve ser inicialmente pontuada no planejamento. Vinculado a esta atividade deve estar o orçamento, que para Nunes (2009), se constitui em um instrumento de distribuição de renda e de justiça social a população, uma decisão democrática de suas prioridades e desejos, transparente e de controle social, com força de lei e com uma boa divulgação.

O orçamento é um plano de trabalho que no Brasil é elaborado e executado pelo poder executivo, sendo o legislativo responsável por sua aprovação e controle e que sumariamente pretende destacar o custeio dos serviços públicos, os investimentos e os meios para obter os recursos para custeá-lo e realizá-lo.

Na administração pública, são utilizados alguns modelos padrões, ou melhor, técnicas orçamentárias que no entendimento Piscitelli e Timbó (2010), sintetizam o planejamento de suas ações e ao adotar uma das técnicas, o ente público deve atentar-se para aos princípios orçamentários.

Além destes princípios, também faz necessário seguir na íntegra as demais leis que regem o orçamento público. Desde modo, a Constituição Federal em seu artigo 165 depõe sobre este assunto ao afirmar que é de competência do poder executivo o planejamento 
e a execução das políticas públicas no Brasil, que ocorre mediante o plano plurianual (PPA), as diretrizes orçamentárias (LDO) e os orçamentos anuais (LOA). Instrumentos que compõem o sistema orçamentário nacional.

Estes planos de trabalho são obrigatórios e devem ser elaborados e colocados em prática pela administração pública, a fim de organizar suas receitas e despesas em um determinado período de tempo. Neste sentido, o planejamento orçamentário segue algumas etapas denominadas de ciclo orçamentário que correspondem sucessivamente a sua elaboração, o seu estudo e aprovação, a sua execução e avaliação (SILVA, 2013).

A primeira etapa compreende a fixação dos objetivos para um determinado período, tendo como base os cálculos referentes às pessoas, aos recursos materiais e financeiros os quais serão necessários para sua materialização e concretização. Os estudos e a aprovação por sua vez são de competência do Poder Legislativo, os quais devem considerar as necessidades da população e a melhor forma de saná-las. Já a execução, se refere à concretização anual dos objetivos e das metas estabelecidas pelo poder público, enquanto a avaliação busca julgar a sua realização (SILVA, 2013).

Diante destes comentários, observa-se a importância do orçamento público à sociedade, como um planejamento estratégico das ações de governo.

\section{ORÇAMENTO PÚBLICO MUNICIPAL}

O Orçamento Público Municipal conforme Santos (2015, p. 4), representa "um plano de atividades do governo, onde estão discriminados os serviços que ele preta aos cidadãos e quanto eles custam". Salienta que não só os serviços estão discriminados neste documento, mais também todos os bens e os recursos necessários à sua execução e deste modo ele mostra "de forma clara e precisa o montante de impostos a ser arrecadado e o detalhamento criterioso de sua destinação" (GAETANI, GONÇALVES e BUVINICH, 2000, p. 62).

A elaboração deste documento deve estar em consonância com o PPA, a LDO a LOA, constituindo assim o Sistema Orçamentário Nacional.

O PPA representa "uma síntese dos esforços de planejamento de toda a administração pública, orientando a elaboração dos demais planos e programas de governo, assim como do próprio orçamento anual" (GIACOMONI, 2010, p. 219). Trata das intenções do governo, seus propósitos, as diretrizes, os objetivos e metas da administração pública para as despesas de capital e outras decorrentes de programas de duração continuada. Refere-se em geral de três a quatros anos.

A LDO orienta a elaboração da lei orçamentária anual e a sua execução, devendo ser realizada anualmente e compreende as metas e prioridades da administração pública incluindo as despesas de capital para o exercício financeiro subsequente.

E, a LOA, deve conter as estimativas da receita e a fixação das despesas da administração pública para o exercício financeiro, incluindo o orçamento fiscal, de investimentos e de seguridade social. 


\section{TÉCNICAS ORÇAMENTÁRIAS PRINCÍPIOS ORÇAMENTÁRIOS}

Técnica orçamentária caracteriza-se o meio pelo qual o gestor irá organizar a previsão da entrada de recursos no caixa, bem como a forma como ele pretende gastar, utilizar estes recursos quer em despesas correntes ou em despesas de capital. O quadro 1 apresenta as técnicas orçamentárias e suas funções básicas.

Quadro 1: Técnicas orçamentárias e suas funções básicas

\begin{tabular}{|c|c|}
\hline $\begin{array}{c}\text { Técnicas } \\
\text { orçamentárias }\end{array}$ & Funções básicas \\
\hline $\begin{array}{l}\text { Orçamento } \\
\text { Clássico } \\
\text { tradicional }\end{array}$ & $\begin{array}{l}\text { Produzir um documento de } \\
\text { previsão de receita e autorização } \\
\text { de despesa, onde a preocupação } \\
\text { principal é com a classificação das } \\
\text { despesas por objeto de gastos. }\end{array}$ \\
\hline $\begin{array}{lr}\text { Orçamento } & \text { por } \\
\text { Realização } & \text { ou } \\
\text { desempenho } & \end{array}$ & $\begin{array}{l}\text { Verificar o que o governo realiza e } \\
\text { não apenas o que compra, busca } \\
\text { interligar os objetivos de gastos } \\
\text { aos objetivos específicos das ações } \\
\text { de governo. }\end{array}$ \\
\hline $\begin{array}{l}\text { Orçamento } \\
\text { Programa }\end{array}$ & $\begin{array}{l}\text { Permitir a interligação do } \\
\text { planejamento com o orçamento } \\
\text { por meio de programas de } \\
\text { governo, que é expresso por um } \\
\text { conjunto de ações a serem } \\
\text { realizadas, onde se identificam os } \\
\text { recursos necessários a sua } \\
\text { execução. }\end{array}$ \\
\hline $\begin{array}{l}\text { Orçamento } \\
\text { Base } \\
\text { Zero ou por } \\
\text { estratégia }\end{array}$ & $\begin{array}{l}\text { Exige de cada administrador a } \\
\text { justificativa detalhada dos recursos } \\
\text { solicitados. Análise concentrada } \\
\text { em objetivos e necessidades, em } \\
\text { virtudes das justificativas que } \\
\text { devem ser apresentadas para cada } \\
\text { item de despesas. }\end{array}$ \\
\hline $\begin{array}{l}\text { Orçamento } \\
\text { Participativo }\end{array}$ & $\begin{array}{llll}\text { Promover a participação } & \text { da } \\
\text { sociedade na discussão } & \text { de } \\
\text { investimento } & \text { do orçamento } \\
\text { público. } & & \end{array}$ \\
\hline
\end{tabular}

Fonte: Adaptado de Mota (2009) e Silva (2013).

Independentemente de qual técnica é escolhida tem-se que atentar para os princípios orçamentários durante todo o seu processo, conforme o Quadro 2.
Quadro 2: Princípios orçamentários

\begin{tabular}{|c|c|}
\hline $\begin{array}{c}\text { Princípios } \\
\text { orçamentários }\end{array}$ & Funções \\
\hline Unidade & $\begin{array}{l}\text { As receitas previstas e as despesas } \\
\text { fixadas, em cada exercício } \\
\text { financeiro, devem integrar um } \\
\text { único documento. }\end{array}$ \\
\hline Universalidade & $\begin{array}{l}\text { O orçamento deverá conter todas } \\
\text { as receitas e despesas de todos os } \\
\text { poderes, órgãos, entidades, } \\
\text { fundos e fundações instituídas e } \\
\text { mantidas pelo Poder Público. }\end{array}$ \\
\hline Anualidade & $\begin{array}{l}\text { Delimita o exercício financeiro } \\
\text { orçamentário que deverá coincidir } \\
\text { com o ano civil: } 1 \text { de janeiro a } 31 \\
\text { de dezembro de cada ano. }\end{array}$ \\
\hline Exclusividade & $\begin{array}{l}\mathrm{O} \text { orçamento não deve conter } \\
\text { dispositivo estranho à previsão da } \\
\text { receita e à fixação da despesa. }\end{array}$ \\
\hline Orçamento bruto & $\begin{array}{l}\text { As receitas e as despesas devem } \\
\text { ser registradas pelo seu valor total } \\
\text { bruto, sendo vedadas quaisquer } \\
\text { deduções. }\end{array}$ \\
\hline Legalidade & $\begin{array}{l}\text { Cabe ao Poder Público fazer ou } \\
\text { deixar de fazer somente aquilo } \\
\text { que a lei expressamente autorizar. }\end{array}$ \\
\hline Publicidade & $\begin{array}{l}\text { O orçamento deve ser público e } \\
\text { amplamente divulgado para que } \\
\text { todos possam ter acesso as suas } \\
\text { informações. }\end{array}$ \\
\hline Transparência & $\begin{array}{l}\text { O orçamento deve ser divulgado } \\
\text { de forma ampla à sociedade; } \\
\text { publicar relatórios sobre a } \\
\text { execução orçamentária e a gestão } \\
\text { fiscal; disponibilizar, para } \\
\text { qualquer pessoa, informações } \\
\text { sobre a arrecadação da receita e a } \\
\text { execução da despesa. }\end{array}$ \\
\hline $\begin{array}{ll}\text { Não vinculação } \\
\text { (não afetação da } \\
\text { receita } & \text { de } \\
\text { impostos) }\end{array}$ & $\begin{array}{l}\text { É proibido vincular a receita a } \\
\text { criação de impostos a órgão, } \\
\text { fundo ou despesa, salvo exceções } \\
\text { estabelecidas pela própria } \\
\text { Constituição Federal, como a } \\
\text { saúde. }\end{array}$ \\
\hline
\end{tabular}

Fonte: Adaptado de Brasil (2013).

Estes princípios correspondem às premissas básicas a serem observadas quando da elaboração da proposta orçamentária. E a sua adoção evidencia a preocupação, o cuidado e a atenção que o gestor tem relação aos recursos públicos e suas destinações. 


\section{METODOLOGIA}

Esta pesquisa se caracteriza como exploratória, ao buscar "desenvolver, esclarecer e modificar conceitos e ideais a fim de fornecer hipóteses pesquisáveis para estudos posteriores" (TRUJILLO FERRARI, 1982, p. 180). E também no segundo momento ela é descritiva por observar, registrar, e analisar e correlacionar fatos, fenômenos, ou mesmo situações, sem a pretensão de manipulá-los (GIL, 2002). Dentro dos preceitos de um estudo desta natureza, optou-se em dividi-lo em duas etapas, a saber: a primeira pesquisar os assuntos contemplados neste trabalho por meio de artigos e textos já produzidos e publicados (pesquisa em fontes secundárias), e a segunda um estudo do tipo survey, a fim de obter dados e ou informações sobre características, ações ou opiniões de grupo de pessoas, utilizando-se de instrumentos de pesquisas como o questionário.

Quanto à abordagem do problema, o trabalho apresenta aspectos qualitativos por descrever, analisar a interação das variáveis, compreender e classificar processos dinâmicos vivenciados por grupos sociais, contribuir no processo de mudança, criação ou formação de opiniões de grupos e possibilitar o entendimento das particularidades das pessoas.

Para coletar os dados utilizou-se de questionários, com questões predominantemente fechadas direcionando-os aos responsáveis pela elaboração do Orçamento Público, via e-mail (eletronic mail). Após, o envio dos questionários obteve o retorno de 9 Prefeituras (Anastásio; Caarapó; Dourados; Itaquarí; Miranda; Nova Andradina; Paraiso das Águas; Ponta Porã e
Douradina) que se propuseram a participar da pesquisa, ou seja: $11,39 \%$ do total de 79 questionários enviados.

\section{APRESENTAÇÃO E ANÁLISE DOS DADOS}

Situado na Região Centro-Oeste do país, o Estado de Mato Grosso do Sul, foi constituído a partir do desmembramento do Estado de Mato Grosso no ano de 1979. As principais fontes econômicas do Mato Grosso do Sul cuja capital é a cidade de Campo Grande são: a agricultura a pecuária (SEMADE, 2015).

De acordo com o IBGE, a população do Estado em 2015 era de aproximadamente 2.651.235 milhões habitantes distribuídos em 79 Municípios.

Dentre as cidades pesquisadas a mais populosa é Dourados com 212.870 mil habitantes; Ponta Porã com 86.717 mil; Nova Andradina com 50.893 mil; Caarapó, com 28.437 habitantes; Miranda, com 27.104; Anastásio, com 24.748; Itaquarí, com 20.162; Douradina com 5.723 e por fim, Paraiso das Águas com 5.150 habitantes.

Pelo contexto das cidades do estado é possível identificar que participaram da pesquisa cidades consideradas de Grande, Médio e Pequeno porte no que se refere à população.

Quanto aos respondentes da pesquisa todos são do gênero masculino. 7, deles possuem curso superior e todos os 9, ocupam cargos que estão diretamente relacionados ao processo orçamentário de seus respectivos Municípios, possuindo assim dados e informações referente aos questionamentos realizados a respeito das 
Técnicas Orçamentárias utilizadas e demais questões relacionados a esta temática.

\section{ORÇAMENTOS DAS PREFEITURAS}

Os questionamentos a respeito do orçamento das prefeituras buscaram informações a respeito das técnicas orçamentárias utilizadas na composição de seu orçamento; Qual motivo de sua adoção; Se há uma revisão desta técnica; Quem são os responsáveis em elaborar o orçamento; Se a população participa deste processo; Se há reuniões públicas para discutir o orçamento; Se os princípios orçamentários estão sendo respeitados; Quais as prioridades do orçamento; Onde estão sendo aplicada a maior parte dos recursos do orçamento; $\mathrm{Se}$ as necessidades da população são contempladas; E quais as dificuldades quanto à elaboração a sua elaboração e execução.

Em relação às Técnicas Orçamentárias, predomina a utilização por parte das Prefeituras do Orçamento Programa, 67\% das Prefeituras utilizam-se desta técnica e as demais 33\% utilizam do Orçamento Clássico.

Dentre os motivos para a adoção do Orçamento Programa pelos gestores, foi mencionado o fato deste tipo de orçamento garantir que as necessidades do Município estejam alocadas de maneira transparente na peça orçamentária e também o cumprimento da Lei n. 4.320/64 e o Decreto de Lei No 200/1967.

Em relação à participação das pessoas na elaboração do Orçamento Público Município, todos os respondentes afirmaram que realizam audiências públicas, a fim de discutir a alocação das receitas e a fixação das despesas, uma vez que há a obrigatoriedade legal para se fazê-la, o que ocorre pela apresentação e discussão destes assuntos na Câmara Municipal. Neste processo destaca-se o Município de Nova Andradina que anterior a esta discussão na Câmara, a apresentação do orçamento e dos assuntos a ele correlatos são discutidos nos Conselhos Regionais, os quais são formados por cinco pessoas cada um eleitos por suas respectivas comunidades regionais com mantado de dois anos (não se mencionou quantos conselhos existem na cidade, como é o encaminhamento das propostas ao orçamento municipal, e se todas as pessoas da cidade tem conhecimento destes conselhos e também da possibilidade de participação).

Em relação aos princípios orçamentários, das prefeituras pesquisadas, uma delas não se dispôs a responder a este questionamento. Enquanto 4 afirmaram utilizarse de todos os princípios (unidade, anualidade, universalidade, exclusividade, orçamento bruto, legalidade, publicidade, transparência e não vinculação (não afetação) da receita de impostos), na elaboração de seu orçamento. No entanto, outro respondente destacou que a Prefeitura onde ele trabalha adota estes princípios, exceto o da Unidade e do Orçamento Bruto, enquanto outro mencionou a adoção da Anualidade, Publicidade, Legalidade e Transparência, e outro ainda destacou como fundamental observar somente os princípios da Unidade, Universalidade e da Transparência e um respondente declarou respeitar somente o Princípio da Anualidade.

A adoção parcial por parte de algumas Prefeituras em relação aos princípios 
orçamentários é preocupante, uma vez que eles são expostos na Constituição Federal de 1988; Lei 4.320/64 e o Decreto de Lei No 200/1967; Lei de Responsabilidade Fiscal, devendo ser observados em sua integridade, por serem considerados a base para a elaboração do orçamento público.

Portanto, ressalta a importância de adotar os princípios na elaboração do orçamento, uma vez que eles irão dar mais confiabilidade às informações expostas na peça orçamentária.

Quanto às prioridades da administração pública em relação à elaboração do orçamento público, todos respondentes pontuaram que uma das prioridades no que se refere à elaboração do orçamento público municipal é atender as necessidades da população em geral como preconizou a literatura pesquisada. No entanto, faz necessário atentar para o não direcionamento destas preocupações a determinado setores, bem como o não desrespeito aos Princípios Constitucionais da Administração Pública, mais especificamente o princípio da impessoalidade, que de acordo com o artigo 37 da Constituição Federal de 1998, afirma que o objetivo das atividades administrativas de qualquer ente público deve ser pautado pelo interesse público devendo assim se sobressair de qualquer outro interesse quer seja de determinados grupos de pessoas, ou setores econômicos ou mesmo os pessoais (CONSTITUIÇÃO FEDERAL DE 1998).

Em relação à aplicação dos recursos municipais, solicitou dos respondentes pontuar dentre os setores: (Segurança pública; Transporte; Assistência Social; Lazer; Saúde; Infraestrutura; Educação; Meio Ambiente;
Cultura; Saneamento básico; Urbanismo; Turismo; Habitação; Administração pública; Comércio; Energia; Agricultura; Tecnologia; Indústria e outros a serem evidenciados), qual ou quais são mais beneficiados pela administração pública em relação à aplicação dos recursos municipais.

Os setores de Educação e Saúde são os mais beneficiados pelas Prefeituras em relação à destinação de maior parte dos seus recursos, o que não quer dizer que os gestores não direcionam recursos á outras áreas e setores, mais direcionam a maior parte deles. E, deste modo, todos os respondentes relataram que estão atendendo as necessidades da população em termos de serviços e obras públicas.

A respeito das dificuldades quanto à elaboração e execução do Orçamento Público Municipal, os respondentes mencionaram que dentre as dificuldades as que mais se destaca refere-se à dificuldade da administração pública em garantir que as receitas sejam maiores que as suas despesas e assim tentar pelo menos o equilíbrio orçamentário. Outra dificuldade mencionada se refere à dificuldade em atender a comunidade em geral, sendo esta uma das prioridades mais citadas pelos respondentes quando da elaboração do orçamento e segundo os mesmo respondentes embora tenham dificuldades eles conseguem os anseios da população em relação aos serviços e bens públicos. Outra dificuldade bem pontuada foi em relação à definição de metas e prioridades da administração pública. 


\section{CONCLUSÕES}

As Técnicas Orçamentárias representam o processo de formalização do Orçamento Público, ou seja, é a maneira pela qual os gestores públicos dispõem para apresentar as receitas previstas para serem utilizadas e a fixação das despesas para poderem alcançar suas metas e seus objetivos.

Desde modo, realizou-se uma pesquisa por meio do envio de questionário por e-mail aos responsáveis pela elaboração do Orçamento Público de todos os 79 Municípios do estado, além de contato telefônico com alguns responsáveis solicitado a gentileza em responder à pesquisa. Mas mesmo, assim, deste total de Prefeitura somente 9 se disponibilizaram a responder aos questionamentos e assim contribuir com o Trabalho.

No entanto, apesar desta dificuldade foi possível contar com a colaboração dos representantes destes Municípios que trabalham diretamente com as questões orçamentárias. Além disto, também se pode verificar que dentro do contexto populacional do estado de Mato Grosso do Sul, as prefeituras que se propuseram a participar desta pesquisa podem ser classificadas em pequenos, médios e grandes.

Em relação aos questionamentos, verificou-se que mais da metade destes municípios adotam como técnica orçamentária o Orçamento-Programa, uma vez que ele representaria com mais fidedignidade as ações do gestor e onde os recursos seriam aplicados, e também por ser uma das exigências da Legislação que regem as questões e os assuntos pertinentes ao Orçamento Público. No entanto, é preocupante a não adoção integral dos Princípios Orçamentários, como mencionando por alguns respondentes, uma vez que eles representam a base tanto que no se refere à elaboração do orçamento público, quanto também em relação à divulgação dos dados e informações neles dispostos.

Quantos as prioridades em relação ao processo de elaboração do orçamento, a maioria dos respondentes relataram a necessidade de atender a população em geral no que tange a oferta de serviços públicos e de bens públicos. No entanto, destaca-se a atenção a este processo de elaboração, para que não ocorram desvios em relação a esta prioridade principal, ou esta única prioridade conforme destacou a literatura pesquisada.

A maioria dos recursos das receitas previstas segundo os respondentes são destinadas a atender a Educação e a Saúde, conforme disciplina a Constituição Federal de 1998 e as legislações pertinentes a esta matéria às quais preconizam o montante mínimo a ser aplicado nestas áreas. Vale ressaltar que também há áreas e setores que deveriam ser incluídas nestas prioridades e mesmo assim não são como, por exemplo, a área de Saneamento básico que não foi mencionado por nenhum dos respondentes e que se julga de suma importância principalmente por sua relação direta com a área da Saúde.

Ademais, apenar destes comentários, todos os responsáveis pelas informações expostas no questionário enfatizam que atender as necessidades da população em relação aos seus anseios no que se refere à prestação de serviços e bens públicos e mesmo assim reafirmam que a atenção a estas necessidades 
(serviços e bens públicos) representam uma das dificuldades encontradas quando da elaboração e execução orçamentária, além da maior dificuldade que seria a de garantir que as receitas sejam maiores que as despesas o que sinaliza mesmo que implicitamente a dificuldade dos responsáveis em elaborar o orçamento público municipal, bem como os gestores em melhor planejar as suas ações e programas, bem como em executá-los.

\section{REFERÊNCIAS}

BRASIL. Constituição Federal, de 05 de outubro de 1988. Disponível em:

<http://www.camara.gov.br/internet/comissao/index/m ista/orca/Legisla_CMO/const_fed.html>. Acesso em: 15 agosto de 2016 .

BRASIL. Secretaria do Tesouro Nacional. Manual de contabilidade aplicada ao setor público: aplicado à União e aos Estados, Distrito Federal e Municípios/Ministério da Fazenda, Secretaria do Tesouro Nacional. 5. ed. Brasília: Secretaria do Tesouro Nacional, Subsecretaria de Contabilidade Pública. Coordenação-Geral de Normas de Contabilidade Aplicadas à Federação, 2013. Disponível em: <http://www.tesouro.fazenda.gov.br/mcasp1.> 15 Acesso em: 15 agosto de 2016.

ESTATÍSTICA, IBGE - Instituto Brasileiro de Geografia e. Informações sobre os municípios brasileiros. Disponível em:

<http://www.cidades.ibge.gov.br/xtras/temas.php?lang $=\&$ codmun $=500627 \&$ idtema $=144 \&$ search $=$ matogrosso-do-sul|paraiso-das-Águas|financas-publicas2014>. Acesso em: 22 jul. 2016.

GAETANI; F; GONÇALVES; M. E. R. O.; BUVINICH; M. R. Orçamento Público: Entendendo Tudo. Minas Gerais, UNICEF e FUNDAÇÃO JOÃO PINHEIRO, 2000. Disponível em: < http://leaozinho.receita.fazenda.gov.br/biblioteca/Arqu ivos/entendendo.pdf>. Acesso em 20 de julho de 2016.

GIACOMONI, J. Orçamento público. 15. ed. São Paulo: Atlas, 2010.

GIL, A. C. Como elaborar projetos de pesquisa. 5. ed. São Paulo; atlas, 2010.
INSTITUTO BRASILEIRO DE GEOGRAFIA E ESTATISTICA. Censo demográfico 1960, 1970, 1980, 1991, 2000 e 2010. Disponível em: <http://www.censo2010.ibge.gov.br/sinopse/>. Acesso em: 08 de novembro de 2014.

\section{MATO GROSSO DO SUL - SECRETARIA DE ESTADO DE MEIO AMBIENTE E}

DESENVOLVIMENTO ECONOMICO - SEMADE.

Diagnóstico socioeconômico de Mato Grosso do Sul 2015. Disponível em:

file:///D:/Documentos/Desktop/Diagnostico_Socioeco nomico_de_MS_20151.pdf. Acesso em 20 de agosto de 2016.

MOTA, F. G. L. Contabilidade aplicada ao setor público: Brasília: Mota, 2009.

NUNES, K. Orçamento público: orientações para incidir em políticas públicas/Texto Instituto Caliandra. 2. ed. Belo Horizonte : Oficina de Imagens, 2009.

PISCITELLI, R. B. TIMBÓ, M. Z. F. Contabilidade pública: uma abordagem da administração financeira pública. São Paulo: Atlas, 2010.

QUINTANA, A. C; MACHADO, D, P; QUARESMA, J. C. C.; MENDES, R. C.

Contabilidade pública: de acordo com as novas normas brasileiras de contabilidade aplicadas ao setor público e a Lei de Responsabilidade Fiscal. São Paulo: Atlas, 2011.

SANTOS, A J. Orçamento público e os municípios: alguns conceitos de orçamentos e suas repercussões na administração pública municipal. Disponível em: <http://www.lume.ufrgs.br/bitstream/handle/10183/19 441

Marco Aurélio Batista de Sousa

Doutor em Engenharia e Gestão do Conhecimento Universidade Federal de Santa Catarina. Docente do Curso de Ciências Contábeis - Universidade Federal de Mato Grosso do Sul, Câmpus de Três Lagoas.

\begin{tabular}{l}
\hline Ana Letícia Lima de Oliveira \\
Bacharel em Ciências Contábeis - Universidade \\
Federal de Mato Grosso do Sul.
\end{tabular}

Nilton Cezar Carraro
Doutor em Engenharia de Produção - Universidade
Metodista de Piracicaba Docente do Curso de
Ciências Contábeis - Universidade Federal de Mato
Grosso do Sul, Câmpus de Três Lagoas.

